\title{
PENGURANGAN COD DAN BOD LIMBAH CAIR TEROLAH INDUSTRI PENYAMAKAN KULIT MENGGUNAKAN TAMAN TANAMAN AIR DENGAN TANAMAN MELATI AIR
}

\section{COD AND BOD REMOVAL OF TREATED TANNERY WASTEWATER USING CONSTRUCTED WETLAND WITH ECHINODORUS PALAEFOLIUS VEGETATION}

\author{
Prayitno \\ Balai Besar Kulit, Karet dan Plastik, Yogyakarta \\ Email: Prayitno_bbkkp@yahoo.com
}

Diterima: 8 Maret 2013 Direvisi: 22 Mei 2013 Disetujui: 11 Juni 2013

\begin{abstract}
A research was performed to treat the treated tannery wastewater using mexican swordplant (Echinodorus palaefolius) in constructed wetland. It was designed by uplow system with 3 $m \times 1 \mathrm{~m} \times 1 \mathrm{~m}$ in dimension equal with $3 \mathrm{~m}^{3}$ in volume, whereas the media consist of $0.3 \mathrm{~m}$ thick first layer of rock in the bottom; $0.3 \mathrm{~m}$ thick gravel in second layer and $0.1 \mathrm{~m}$ third layer of Black sugar-palm fiber and at the top was sand layer with $0.3 \mathrm{~m}$ in thickness. The experiment was run by $C O D$ and BOD loading varied at $0.137 ; 0.137 ; 0.392 ; 0.409 ; 0.643 ; 0.648 \mathrm{~kg} / \mathrm{d}$ for COD and $0.049 ; 0.051 ; 0.125 ; 0.133 ; 0.464 ; 0.467 \mathrm{~kg} / \mathrm{d}$ for BOD. Effectivity of constructed wetland was determined by $C O D$ and BOD removal. Optimum effectivity of COD removal by $68.75 \%$ was found by operational condition of influent debit $0.576 \mathrm{~m}^{3} / d$; detention time 2 days and 2 hours; $C O D$ loading $0.405 \mathrm{~kg} / \mathrm{d}$, whereas optimum effectivity of the BOD removal by $61.79 \%$ was found by operational condition at influent debit $1.440 \mathrm{~m}^{3} / d$; detention time 1 days 13 hours and 30 minutes and COD loading $0.466 \mathrm{~kg} /$ d and reducing constant $(\mathrm{k})=0.008 \mathrm{~d}^{-1}$.
\end{abstract}

Keywords: constructed wetland, treated tannery wastewater, Echinodorus palaefolius

\begin{abstract}
ABSTRAK
Telah dilakukan penelitian untuk mengolah limbah cair terolah industri penyamakan kulit dengan metode taman tanaman air menggunakan tanaman Melati air (Echinodorus palaefolius). Penelitian ini dilakukan dengan membangun taman tanaman air yang memiliki dimensi panjang $\mathrm{x}$ lebar $\mathrm{x}$ dalam yaitu $3 \mathrm{~m}$ x $1 \mathrm{~m}$ x $1 \mathrm{~m}$ atau identik dengan volume sekitar $3 \mathrm{~m}^{3}$. Media pengisi taman tanaman air dibuat dari: lapisan paling bawah koral ketebalan $0,3 \mathrm{~m}$, lapisan kedua kerikil dengan diameter ketebalan $0,3 \mathrm{~m}$, lapisan ketiga ijuk dengan ketebalan $0,1 \mathrm{~m}$ dan lapisan paling atas berupa pasir dengan ketebalan 0,3 m, sistem aliran menggunakan sistem upflow. Tanaman yang digunakan adalah tanaman Melati air (Echinodorus palaefolius var. Latifolius). Perlakuan operasional dengan memvariasi COD dan BOD loading, berturut-turut untuk COD: 0,137; 0,$137 ; 0,392 ; 0,409 ; 0,643 ; 0,648 \mathrm{~kg} / \mathrm{d}$ sedangkan untuk $\mathrm{BOD}_{5}: 0,049 ; 0,051 ; 0,125 ; 0,133 ; 0,464$ dan $0,467 \mathrm{~kg} / \mathrm{d}$. Efektivitas kerja taman tanaman air diukur dengan penurunan kadar $\mathrm{BOD}_{5}$ dan COD. Efektivitas optimal penggurangan COD limbah yang telah diolah dengan taman tanaman air sebesar $68,75 \%$ diperoleh pada perlakuan dengan debit influent $0,576 \mathrm{~m}^{3} / \mathrm{d}$, waktu tinggal 2,083 hari dengan $\mathrm{COD}$ loading $0,405 \mathrm{~kg} / \mathrm{d}$, sedangkan untuk pengurangan $\mathrm{BOD}_{5}$ efektivitas pengurangan sebesar $61,79 \%$ diperoleh pada perlakuan dengan debit influent $1,440 \mathrm{~m}^{3} / \mathrm{d}$, waktu tinggal 1,563 hari dengan COD loading $0,464 \mathrm{~kg} / \mathrm{d}$, diperoleh konstanta $\mathrm{k}=0,008 \mathrm{~d}^{-1}$.
\end{abstract}

Kata kunci: Taman tanaman air, air limbah penyamakan terolah, melati air 


\section{PENDAHULUAN}

Wetland dapat didefinisikan sebagai suatu area yang tergenangi air secara intermitten (Campbell and Ogden, 1999), dengan kedalaman air tipikal kurang dari 0,6 $m$ yang mendukung pertumbuhan tanaman air emergent (Metcalf and Eddy, 2003). Wetland dibedakan menjadi dua yaitu Natural wetland dan Constructed wetland (yang selanjutnya disebut Taman tanaman air). Natural wetland merupakan suatu area yang sudah ada secara alami dengan debit dan struktur yang tidak direncanakan, misalnya rawa-rawa pesisir pantai atau mangroove wetland. Natural wetland banyak ditumbuhi oleh vegetasi emergent, misalnya Thypa sp, Phragmites $s p$, Carex sp, Scirpus sp, Juncus sp dan spesies tanaman rumput-rumputan yang lain. Sedangkan Constructed Wetland atau disebut taman tanaman air merupakan wetland yang dikelola dan dikontrol oleh manusia untuk keperluan penyaring air buangan dengan menggunakan tanaman, aktivitas mikroba dan proses lainnya (Hesket and Bartholomew, 2001). Menurut Hammer (1989), wetland mengolah limbah secara alami yang terdiri dari tiga faktor utama, yaitu: (1) Area yang digenangi air dan mendukung hidupnya tanaman air jenis Hydrophita, (2) Media tumbuh berupa tanah yang selalu digenangi air, (3) Media jenuh air.

Sistem wetland dikonstruksikan sedemikian rupa seperti aslinya dimana di dalamnya diisi dengan batuan, tanah dan zat organik untuk mendukung tanaman-tanaman emergent. Variabel dalam wetland yang strukturnya direncanakan adalah: (1) Debit yang mengalir; (2) Bahan organik tertentu; (3) Kedalaman media tanah; (4) Pemeliharaan tanaman selama proses pengolahan.

Menurut Langergraber (2008) dan Lee et al. (2009) wetland dapat dibedakan menjadi dua tipe. Tipe pertama yaitu wetland dengan aliran di atas permukaan tanah (Free Water Surface System), sistem ini berupa kolam atau saluran-saluran yang dilapisi lapisan kedap air di bawah saluran atau kolam yang berfungsi untuk mencegah merembesnya air keluar kolam atau saluran. Kemudian kolam tersebut terisi tanah sebagai tempat hiduptanaman yang hidup. Tipe kedua yaitu Wetland dengan aliran dibawah permukaan tanah (Sub- surface flow system). Pada sistem ini pengolahan limbah terjadi ketika air mengalir secara perlahan melalui tanaman yang ditanam pada media berpori, misalnya gravel, kerikil dan tanah. Dalam sistem ini tanaman melalui akar rhizoma yang mentransfer oksigen kedalam media subsurface dan menciptakan kondisi aerobik. Proses pengolahan air limbah terjadi melalui proses filtrasi, absorbsi oleh mikroorganisme dan adsorpsi polutan oleh tanah. Removal bahan organik pada sistem SSF dibatasi oleh dua faktor yaitu waktu tinggal dan transfer $\mathrm{O}_{2}$ (Crites, 1998). Menurut Lee et al. (2009), dalam wetland akan terjadi proses-proses fisika, kimia dan biologi oleh kumpulan mikrobia, tanaman emergent, penyerapan oleh tanah dan sedimentasi yang ada di lapisan bawah wetland.

Industri penyamakan kulit adalah industri yang mengolah kulit mentah (hide atau skin) menjadi kulit tersamak (leather). Proses tersebut dimaksudkan untuk mengubah sifat-sifat kulit mentah yang mudah mengalami pembusukan dan kerusakan oleh aktivitas mikroorganisme menjadi kulit tersamak yang tahan terhadap aktifitas mikroorganisme dan pembusukan (Sharphouse, 1989). Pada pelaksanaannya proses penyamakan kulit dilakukan melalui beberapa tahapan proses dan pada setiap tahapan proses memerlukan banyak bahan kimia dan air. Kanagaraj et al. (2006) menyatakan bahwa untuk memproses 1 ton kulit mentah akan dihasilkan 45-50 $\mathrm{m}^{3}$ limbah cair, sehingga industri ini sangat potensial menghasilkan limbah dan mencemari lingkungan apabila tidak dilakukan upayaupaya penanganan limbahnya. Pengendalian pencemaran untuk menangani limbah yang terbentuk dilakukan dengan mengolah limbah dengan menggunakan unit pengolahan air limbah. Untuk meningkatkan efisiensi dalam penggunaan air proses yang penggunaannya cukup besar, limbah cair yang telah terolah diupayakan untuk dapat didaur ulang untuk dapat digunakan sebagai air proses. Pengolahan dapat dilakukan salah satunya dengan menggunakan tanaman air melalui konstruksi wetland. Calheiros et al. (2009) telah melakukan penelitian pengolahan limbah cair industri kulit dengan metoda 
wetland dengan menggunakan jenis tumbuhan Typha latifolia dan Pragmites australis. Hasil penelitian menunjukan adanya penurunan kadar COD sampai 92\% dengan debit influent antara $808-2449 \mathrm{mg} / \mathrm{l}$ dan penurunan BOD sebesar 88\% dengan debit influent 420-1000 $\mathrm{mg} / \mathrm{l}$ dan waktu tinggal 2,5 sampai 7 hari. Pada penelitian ini digunakan wetland dengan aliran dibawah permukaan (SSFS), adapun tanaman yang digunakan adalah jenis melati air. Dengan melati air selain diharapkan dapat menaikan kualitas air buangan terolah juga dapat memberikan taman air.

\section{BAHAN DAN METODE}

\section{Bahan Penelitian}

Bahan terdiri atas tanaman air Echinodorus palaefolius (Melati Air), air limbah efluent dari UPAL Laboratorium pengolahan Kulit Sitimulyo, Balai Besar Kulit, Karet dan Plastik, bahan kimia untuk uji COD dan BOD.

\section{Peralatan Penelitian}

Peralatan penelitian terdiri atas unit taman tanaman air, gelas ukur $1000 \mathrm{ml}$, stopwatch, alat pengambil sampel, alat uji COD dan BOD.

\section{Metode Penelitian}

Penelitian ini dilakukan dengan membangun taman tanaman air yang memiliki dimensi (panjang $\mathrm{x}$ lebar $\mathrm{x}$ dalam) adalah $(3 \mathrm{x}$ $1 \times 1) \mathrm{m}^{3}$ atau identik dengan volume sekitar 3 $\mathrm{m}^{3}$. Media pengisi taman tanaman air terdiri dari lapisan paling bawah koral diameter \pm 10 $\mathrm{cm}$ dengan ketebalan $0,3 \mathrm{~m}$, lapisan kedua berupa kerikil dengan diameter $\pm 3 \mathrm{~cm}$ ketebalan 0,3 $\mathrm{m}$ dan lapisan ketiga berupa ijuk dengan ketebalan $\pm 10 \mathrm{~cm}$ dan lapisan paling atas berupa pasir dengan ketebalan $0,3 \mathrm{~m}$, sistem aliran menggunakan sistem upflow. Gambar wetland seperti terlihat pada Gambar 1 sedangkan tanaman Melati air (Echinodorus palaefolius) terlihat pada Gambar 2.

Wetland yang telah siap sebelum dilakukan penanaman tumbuhan air yang digunakan dilakukan pembersihan dengan mengalirkan air sumur, dilakukan sampai 2 hari sehingga air yang keluar dari outlet jernih,

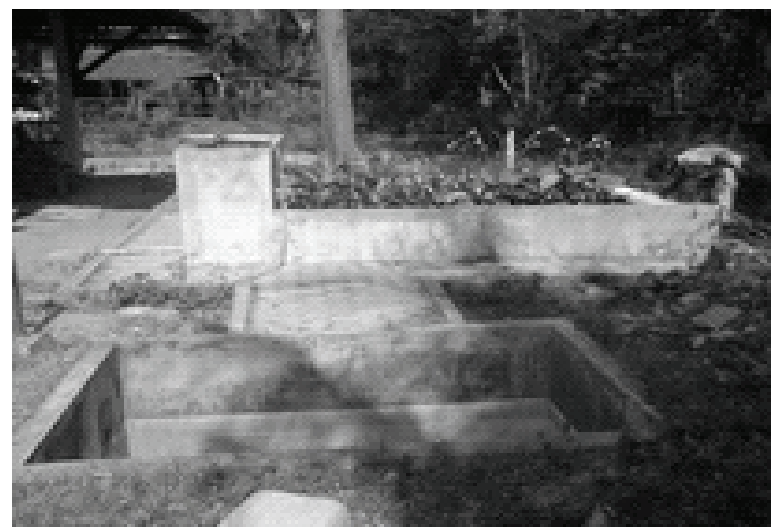

Gambar 1. Taman Tanaman Air (TTA) dengan tanaman melati air

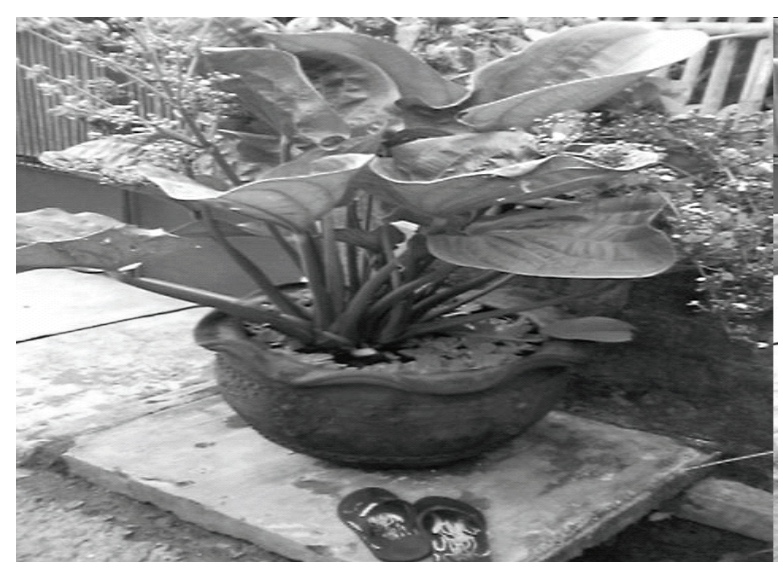

Gambar 2. Melati air (Echinodorus palaefolius)

kemudian dilakukan penanaman tumbuhan untuk penelitian Melati air dengan jarak tanam $50 \mathrm{~cm}$. Tanaman dibiarkan tumbuh dengan air bersih mengalir sampai 2 minggu (tanaman sudah kelihatan berkembang). Kemudian baru dilakukanfeeding dengan limbah terolah. Variabel digunakan adalah COD dan BOD loading dan konsentrasi bahan pencemar didasarkan pada konsentrasi COD dan BOD efluent dari limbah IPAL Laboratorium Sitimulyo. Untuk mengetahui pengurangan $\mathrm{COD}$ dan $\mathrm{BOD}_{5}$ limbah cair terolah yang digunakan dilakukan dengan memvariasi 3 (tiga) perlakuan debit limbah masuk (influent) yaitu 0,$432 ; 0,576$ dan $1,440 \mathrm{~m}^{3} / \mathrm{d}$ dan menghasilkan waktu tinggal 3 hari 3 jam; 2 hari 2 jam dan 1 hari 13 jam 30 menit. Konsentrasi COD dan BOD diukur pada limbah masuk (influent) dan pada limbah yang keluar (effluent) unit TTA.

Terhadap penurunan kadar pencemar masuk (inlet) dan keluar (outlet) dari unit taman tanaman air digunakan untuk 
perhitungan efektifitas pengurangan bahan pencemar sedangkan nilai konstanta penurunan kadar limbah sebagai dasar dalam pembuatan desain taman tanaman air digunakan perhitungan degradasi polutan pada sistem taman tanaman air mengacu formula yang diberikan oleh EPA (1998) dengan formula sebagai berikut:

Dengan asumsi reaksi terjadi adalah reaksi orde 1 ,

$$
\begin{aligned}
& \mathrm{C}_{0}=\mathrm{C}_{1} \mathrm{e}^{-\mathrm{kt}} \\
& \ln \mathrm{C}_{1} / \mathrm{C}_{0}=\mathrm{kt}
\end{aligned}
$$

Dari persamaan (2) akan diperoleh persamaan garis linier $\mathrm{Y}=\mathrm{kX}$

dimana:

$\mathrm{C}_{1}=$ Konsentrasi polutan pada bagian inlet, $\mathrm{mg} / 1$

$\mathrm{C}_{0}=$ Konsentrasi polutan pada bagian outlet, $\mathrm{mg} / 1$

$\mathrm{k}=$ Konstanta kecepatan pada suhu percobaan, $\mathrm{d}^{-1}$

$\mathrm{t}=$ waktu tinggal, $\mathrm{d}$

$$
\begin{aligned}
& \mathrm{t}=\mathrm{V} / \mathrm{Q} \\
& \mathrm{t}=\mathrm{ndA} / \mathrm{Q}
\end{aligned}
$$

dimana:

$\mathrm{V}=$ Volume taman tanaman air (TTA) yang ada untuk aliran mengalir, $\mathrm{m}^{3}$

$\mathrm{n}=$ Porositas, (persen dalam desimal)

$$
=0,75
$$

$\mathrm{d}=$ Kedalaman TTA, $\mathrm{m}$

$\mathrm{A}=$ Luas areal TTA, $\mathrm{m}^{2}$

$\mathrm{Q}=$ Debit rata-rata yang dilewatkan TTA, $\mathrm{m}^{3} / \mathrm{d}$

\section{HASIL DAN PEMBAHASAN}

Penelitian menghasilkan taman tanaman air dengan menggunakan tumbuhan Melati air (Echinodorus palaefolius) dengan sistem Subsurface Flow (SSF) dimana air limbah dialirkan dibawah permukaan, sistem ini merupakan reaktor biologis attached growth dan berfungsi sebagaimana trickling filter dan biological contactors. Kemampuan sistem sangat dipengaruhi oleh waktu detensi air limbah dalam reaktor serta beban limbah yang masuk, kondisi biota dan keterbatasan oksigen dalam sistem. Influent unit TTA merupakan effluent limbah terolah dari unit pengolah air limbah Laboratorium Penyamakan Kulit,

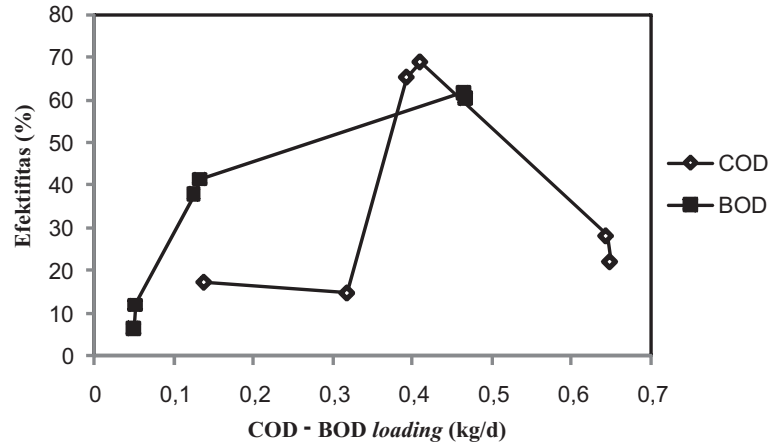

Gambar 3. Efektivitas pengurangan $\mathrm{COB} / \mathrm{BOD}$ padaberbagai loading

Sitimulyo sedangkan effluent adalah yang keluaran dari unit taman tanaman air hasil penelitian. Efektivitas pengurangan COD dan $\mathrm{BOD}_{5}$ dengan berbagai loading rate adalah seperti terlihat pada Gambar 3 .

Dari Gambar 3 terlihat, efektifitas penurunan COD dengan loading $0,137 \mathrm{~kg} / \mathrm{d}$ masih sangat rendah berkisar antara 15-17,5\% dengan debit (influent) limbah terolah 0,432 $\mathrm{m}^{3} / \mathrm{d}$ dan waktu tinggal 3 hari 3 jam, penurunan COD optimum terjadi pada penggunaan debit (influent) air limbah masuk $0,576 \mathrm{~m}^{3} / \mathrm{h}$, dengan waktu tinggal 2 hari 2 jam dengan COD loading $0.409 \mathrm{~kg} / \mathrm{d}$ efektivitas pengurangan rata-rata $66,98 \%$. Vymasal and Kröpfelová (2009), dalam percobaannya penghilangan bahan organik dalam TTA menyatakan bahwa efektivitas pengurangan COD dan BOD untuk limbah industi berturutturut $63,1 \%$ dan $60,1 \%$ sedangkan dari percobaan Debing et al. (2010) dalam percobaan pengurangan COD dengan Sub Surface Wetland menggunakan tumbuhan Phragmites $s p$ diperoleh penurunan COD sampai dengan 75,54\% dengan konsentrasi COD influent $138,2 \mathrm{mg} / \mathrm{l}$. Dalam penelitian ini efektifitas optimum 66,98 \%. Efektivitas pengurangan COD dari TTA menggunakan tumbuhan melati air masih rendah, hal tersebut kemungkinan sesuai mendapat dari Liu et al. (2008) didasarkan bahwa pengurangan COD dalam sistem wetland dilakukan melalui aktivitas fisika, kimia dan biologis. Mikroba mendegradasi bahan organik non recalcitran dan diabsorpsi oleh akar dari tanaman air (Khilji and Bareen, 2008), sehingga rendahnya tingkat efektifitas dalam menurunkan kadar COD pada TTA 
menggunakan tumbuhan malati air ini kemungkinan disebabkan daya absorsi akar yang kurang, dikarenakan sistem bentuk akarnya yang sedikit dimana akar merupakan media attached growth mikroorganisme pendegradasi bahan-bahan organik disamping itu akar tanaman melati air tidak menembus lebih masuk kedalam media, sehingga kemampuan tumbuhan untuk menyerap bahan-bahan organik tidak optimal. Selain dua hal tersebut, air limbah industri kulit banyak menggandung bahan kimia yang dapat menghambat kerja mikroorganisme seperti garam dapur yang menyebabkan tingginya salinitas. Untuk pengurangan BOD, dari Gambar 3 terlihat bahwa semakin tinggi BOD loading, efektivitas pengurangan juga akan semakin tinggi dari data terlihat dengan BOD loading 0,$049 ; 0,051 ; 0,125 ; 0,133 ; 0,464$; $0,467 \mathrm{~kg} / \mathrm{d}$ berturut-turut akan menunjukan kenaikan efektifitas sebesar 6,55; 12,11; 38,$17 ; 61,79 ; 60,53 \%$. Dari analisa varian dengan taraf kepercayaan 95\% diketahui bahwa adanya perbedaan yang signifikan pada setiap kenaikan COD dan BOD loading (Fht $=4,2709>\mathrm{F}$ tbl $=0,1747$ untuk COD dan Fht $=36.7939>\mathrm{F}$ tbl $=0,1747$ untuk BOD). Naiknya bahan organik yang dapat terdegradasi oleh bakteri pada air limbah yang masuk akan menaikan pertumbuhan mikro organisme sehingga akan menaikan kemampuan degradasi bahan organik tersebut dalam limbah tersebut.

Dengan menggunakan formulasi dari EPA (1998) akan diperoleh hasil seperti pada laju penurunan COD maupun BOD seperti terlihat pada Gambar 4.

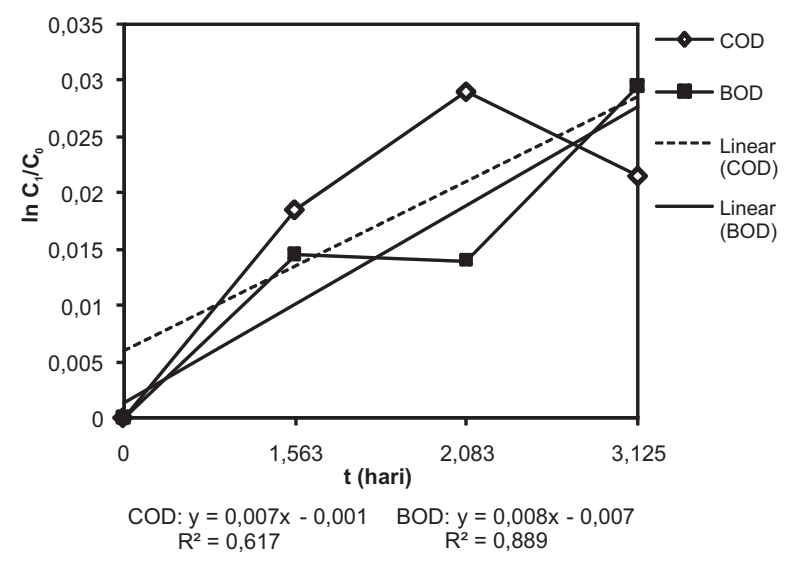

Gambar 4. Grafik Perhitungan Konstanta Laju Pengurangan (k) COD dan BOD
Pada Gambar 4 terlihat bahwa untuk COD, model dari EPA (1998) tidak dapat diterapkan dengan melihat nilai $\mathrm{R}^{2}$ yang rendah sehingga tidak ada hubungan linier antara efektivitas degradasi zat organik dalam limbah dengan waktu tinggal (COD loading), sedangkan untuk BOD menunjukan adanya hubungan liniaritas antara efektivitas pengurangan BOD dengan waktu tinggal (BOD loading) hal tersebut terlihat dari nilai $\mathrm{R}^{2}=0,889$ yang mendekati nilai 1, hasil penelitian Chong et al. (2009) menunjukan nilai $\mathrm{R}^{2}$ berkisar antara 0,850-0,965. Dari percobaan dan setelah diaplikasikan dengan formulasi model dari EPA diperoleh nilai konstanta penurunan BOD $(\mathrm{k})$ sebesar $0,008 \mathrm{~d}^{-1}$.

\section{KESIMPULAN DAN SARAN}

\section{Kesimpulan}

Dari penelitian dapat disimpulkan penggunaan taman tanaman air dengan tanaman melati air memberikan efektivitas optimum penggurangan COD sebesar $66,98 \%$ pada operasional dengan debit $0,576 \mathrm{~m}^{3} / \mathrm{d}$ waktu tinggal 2 hari 2 jam dan dengan COD loading $0,409 \mathrm{~kg} / \mathrm{d}$ sedangkan konstanta laju pengurangan COD $(\mathrm{k})$ tidak dapat dihitung dengan model dari EPA. Efektivitas pengurangan BOD sebesar $61,79 \%$ diperoleh pada perlakuan dengan debit influent 1,440 $\mathrm{m}^{3} / \mathrm{d}$, waktu tinggal 1 hari 13 jam 30 menit dengan BOD loading $0,464 \mathrm{~kg} / \mathrm{d}$, sedangkan nilai konstanta diperoleh $\mathrm{k}=0.008 \mathrm{~d}^{-1}$. Untuk desain TTA dapat digunakan atas dasar pengurangan BOD.

\section{Saran}

Untuk meningkatkan efektivitas dari Taman tanaman air perlu dilakukan penelitian dengan menggunakan tanaman yang mempunyai akar tunggang yang dapat menembus kedalam media lebih dalam sehingga memungkinkan untuk lebih banyak tanaman dapat kontak dengan limbah dalam media.

\section{UCAPAN TERIMA KASIH} kepada:

Penulis mengucapkan terima kasih 1. Bapak Kepala Balai Besar Kulit, Karet dan Plastik, atas arahan-arahan dalam 
pelaksanaan penelitian ini.

2. Kepala Bidang Sarana Riset dan Standardisasi atas ijin untuk penggunaan fasilitas laboratorium.

3. Semua kelompok kerja 1866.01.003 yang telah membantu kami sehingga penelitian ini dapat diselesaikan.

\section{DAFTAR PUSTAKA}

EPA (United States Environmental Protection Agency), 1998. Design manual constructed wetland and aquatic plant system for municipal wastewater treatment, United States Environmental Protection Agency, USA.

Calheiros, C. S. C., Rangel, A. O. S. S. and Castro, P. M. L, 2009. Treatment of industrial wastewater with two-stage constructed wetland planted with Typha latifolia and Phragmites australis, Bioresource Technology, 100: 32053213.

Chong, H. L. H., Ahmad. M. N. and Lim, P. E., 2009. Growth of Typha angustifolia and media biofilm formation in constructed wetland with different media, Borneo Science, 25: 11-21.

Campbell, C. S. and Ogelen, M. H., 1999. Construkted wetland in the sustainable landscape, John Wiley and Sons, NewYork.

Crites, R. and Tchobanoglous, G., 1998. Small and decentralized wastewater management system, McGraw-Hill Companies, USA.

Debing. J., Baoqing, S., Hong. Z., and Jianming, H., 2010. Chemical oxygen demand, nitrogen and phosphorus removal by subsurface wetlands with Phragmites vegetation in different model, Engineering Life Science, 10: 177-183.

Hammer, D. A., 1989. Constructed wetland for wastewater treatment municipal and agriculture, Lewis Publisher, Michigan.
Khilji, S. and Bareen, F. E., 2008. Rhizofiltration of heavy metal from the tannery sludge by anchored hydrophyte, Hydrocotyle umbellate L., African Journal of Technology, 7(20): 37113717.

Heskett and Bartholomew, 2001. Constructed wetland, http://www.epa.gov/owow/wetland/pdf/-overview.pdf.

Kanagaraj, J., Vellapan. K. C, Babu, C. B. N. K. and Sadulla S., 2006. Solid waste generation in the leather industry and its utilization for cleaner Environment-a review, Journal of Scientific and Industrial Research, 65(7): 541-8.

Langergraber. G., 2008. Modeling of processes in subsurface flow constructed wetlend - a review, Vadose Zone Journal, 7(2): 830-842.

Liu, D., Ge, Y., Chang, J., Peng, C., Gu, B., Chan, G. Y. S. and Wu, X., 2008. Constructed wetland in China: recent development and future challenges, Frontiers in Ecology and the Environment, 7(5): 261-268.

Lee, C. G., Fletcher, T. D. and Sun, G., 2009. Nitrogen removal in constructed wetland, Engeneering Life Science, 9(1): 11-23.

Metcalf and Eddy, 2003. Wastewater engineering treatment diposal reuse, McGraw Hill Co., New York.

Sharphouse, J. H., 1989. Leather technician's handbook, Leather Producer Assosiation, London.

Vymazal, J. and Kropfelova. L., 2009. Removal of organics in constructed wetland with horizontal flow: a reviev of the field experience, Science of the Total Environment, 407,3911-3922. 